\title{
Pyridinolyses of 2,4-Dinitrophenyl Phenyl Carbonate and 2,4-Dinitrophenyl Benzoate: Effect of Nonleaving Group on Reactivity and Mechanism ${ }^{\dagger}$
}

\author{
Ik-Hwan Um, ${ }^{*}$ Min Ji Son, ${ }^{\dagger}$ Song-I Kim, and Kalsoom Akhtar
}

\author{
Department of Chemistry and Nano Science, Ewha Womans University, Seoul 120-750, Korea.*E-mail: ihum@ewha.ac.kr \\ †Department of Chemistry, Duksung Women's University, Seoul 132-714, Korea \\ Received April 13, 2010, Accepted May 7, 2010
}

\begin{abstract}
Second-order rate constants $\left(k_{\mathrm{N}}\right)$ have been measured for reactions of 2,4-dinitrophenyl phenyl carbonate (2) with a series of pyridines in $80 \mathrm{~mol} \% \mathrm{H}_{2} \mathrm{O} / 20 \mathrm{~mol} \% \mathrm{DMSO}$ at $25.0 \pm 0.1{ }^{\circ} \mathrm{C}$, and compared with the $k_{\mathrm{N}}$ values reported for the corresponding reactions of 2,4-dinitrophenyl benzoate (1) to investigate the effect of nonleaving group on reactivity and mechanism. The reactions of $\mathbf{2}$ result in larger $k_{\mathrm{N}}$ values than those of $\mathbf{1}$. The Brønsted-type plot for the reactions of 2 exhibits a downward curvature (i.e., $\beta_{2}=0.84$ and $\beta_{1}=0.16$ ), which is typical for reactions reported to proceed through a stepwise mechanism with a change in rate-determining step. The $\mathrm{p} K_{\mathrm{a}}$ at the center of the Brønsted curvature, defined as $\mathrm{p} K_{\mathrm{a}}^{\mathrm{o}}$, has been found to be 8.5 and 9.5 for the reactions of $\mathbf{2}$ and $\mathbf{1}$, respectively. Dissection of $k_{\mathrm{N}}$ into the microscopic rate constants (e.g., $k_{1}$ and $k_{2} / k_{-1}$ ratio) has revealed that the reactions of 2 result in larger $k_{1}$ values than those of $\mathbf{1}$, indicating that $\mathrm{PhO}$ behaves as a stronger electron-withdrawing group than $\mathrm{Ph}$. However, the $k_{2} / k_{-1}$ ratio has been found to be independent of the electronic nature of $\mathrm{Ph}$ and $\mathrm{PhO}$.
\end{abstract}

Key Words: Brønsted-type plot, 2,4-Dinitrophenyl phenyl carbonate, Pyridinolysis, Rate-determining step, Stepwise mechanism

\section{Introduction}

Aminolysis of esters has generally been reported to proceed through a stepwise mechanism with a zwitterionic tetrahedral intermediate $\left(\mathrm{T}^{ \pm}\right)$as shown in Scheme 1, in which the ratedetermining step (RDS) is dependent on the basicity of the incoming amine and the leaving group. ${ }^{1-14}$ The RDS has been suggested to change from breakdown of $\mathrm{T}^{ \pm}$to its formation as the basicity of the incoming amine increases. ${ }^{1-14}$ Evidence provided for a change in RDS is curved Brønsted-type plots often observed for reactions of esters possessing a good leaving group (e.g., 2,4-dinitrophenoxide). ${ }^{1-14}$

The $\mathrm{p} K_{\mathrm{a}}$ at the center of the Brønsted curvature has been defined as $\mathrm{p} K_{\mathrm{a}}{ }^{\mathrm{o}}$ where a change in RDS occurs. ${ }^{8}$ It is now firmly understood that RDS changes from the $k_{2}$ step to the $k_{1}$ process as the incoming amine becomes more basic than the leaving group by 4 to $5 \mathrm{p} K_{\mathrm{a}}$ units or the leaving group becomes less basic than the amine. However, the effect of nonleaving group on $\mathrm{p} K_{\mathrm{a}}{ }^{\mathrm{o}}$ is controversial. ${ }^{8-14}$ Gresser and Jencks have found that the $\mathrm{p} K_{\mathrm{a}}^{\mathrm{o}}$ in quinuclidinolysis of diaryl carbonates increases as the substituent in the nonleaving group of $\mathrm{T}^{ \pm}$changes from an electron-donating group (EDG) to an electron-withdrawing group (EWG), and concluded that an $\mathrm{EWG}$ increases $\mathrm{p} K_{\mathrm{a}}{ }^{\mathrm{o}}$ by decreasing the $k_{2} / k_{-1}$ ratio. ${ }^{8}$ The explanation given is that an EWG in the nonleaving group could increase $k_{-1}$ through the push provided the nonbonding electrons in the oxygen atom

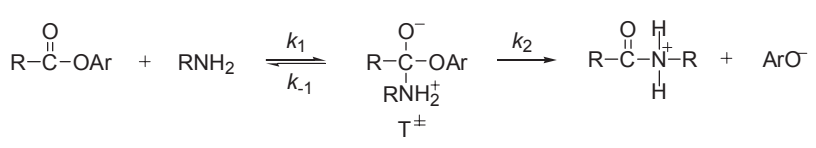

\section{Scheme 1}

${ }^{\dagger}$ This paper is dedicated with respect and affection to the late Professor Chi Sun Hahn, an inspiring teacher and mentor. of the leaving aryloxide. ${ }^{8}$ A similar idea has been proposed for pyridinolysis of 2,4-dinitrophenyl X-substituted benzoates, ${ }^{9}$ aminolysis of $S$-2,4-dinitrophenyl X-substituted thiobenzoates, ${ }^{10}$ pyridinolysis of aryl dithiobenzoates and related esters, ${ }^{11 a, b}$ and theoretical calculations on phenolysis of aryl acetates. ${ }^{11 \mathrm{c}}$

In contrast, we have shown that the $k_{2} / k_{-1}$ ratio is independent of the electronic nature of the substituent $\mathrm{X}$ in the nonleaving group for aminolysis of 2,4-dinitrophenyl X-substituted benzenesulfonates $^{12}$ and related compounds. ${ }^{13,14}$ We have proposed that expulsion of the nucleofuges from $\mathrm{T}^{ \pm}$would be retarded by an EWG but accelerated by an EDG, since both nucleofuges depart with the electrons originally bonded to the remainder of $\mathrm{T}^{ \pm} \cdot{ }^{12-14}$ Thus, $\mathrm{p} K_{\mathrm{a}}^{\mathrm{o}}$ has been concluded to be independent of the electronic nature of the substituent in the nonleaving group. ${ }^{12-14}$

We have recently reported that pyridinolysis of 2,4-dinitrophenyl benzoate (1) proceeds through a stepwise mechanism with a change in RDS at $\mathrm{p} K_{\mathrm{a}}^{\mathrm{o}}=9.5 .^{7 \mathrm{a}}$ Our study has been extended to pyridinolysis of 2,4-dinitrophenyl phenyl carbonate (2) to investigate the effect of changing the $\mathrm{Ph}$ group in $\mathbf{1}$ by $\mathrm{PhO}$ (i.e., changing the substrate from $\mathbf{1}$ to 2 ) on reactivity and mechanism including $\mathrm{p} K_{\mathrm{a}}^{\mathrm{o}}$. It is known that $\mathrm{PhO}$ is a stronger $\mathrm{EWG}$ than $\mathrm{Ph}$ on the basis of their $\sigma_{\mathrm{I}}$ values (e.g., $\sigma_{\mathrm{I}}=0.38$ for $\mathrm{PhO}$ and $\sigma_{\mathrm{I}}=0.10$ for $\left.\mathrm{Ph}\right),{ }^{15 \mathrm{a}}$ while the former is also a stronger EDG than the latter on the basis of their $\sigma_{R}$ values (e.g., $\sigma_{R}=-0.34$ for $\mathrm{PhO}$ and $\sigma_{\mathrm{R}}=-0.11$ for $\left.\mathrm{Ph}\right) .{ }^{15 \mathrm{a}}$ We wish to report that reactions of 2 result in a lower $\mathrm{p} K_{\mathrm{a}}{ }^{\mathrm{o}}$ than those of 1 by $1 \mathrm{p} K_{\mathrm{a}}$ unit although $\mathrm{PhO}$ behaves as a stronger EWG than $\mathrm{Ph}$ in the current reactions, and the $k_{2} / k_{-1}$ ratio is independent of the nature of the nonleaving-group substituent.
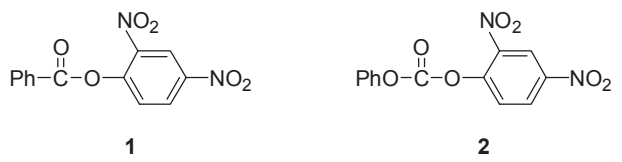
Table 1. Summary of second-order rate constants $\left(k_{\mathrm{N}}\right)$ for reactions of 2,4-dinitrophenyl benzoate (1) and 2,4-dinitrophenyl phenyl carbonate (2) with Z-substituted pyridines in $80 \mathrm{~mol} \% \mathrm{H}_{2} \mathrm{O} / 20 \mathrm{~mol} \% \mathrm{DMSO}$ at $25.0 \pm 0.1{ }^{\circ} \mathrm{C}^{a}$

\begin{tabular}{lcccc}
\hline & \multirow{2}{*}{$\mathrm{Z}$} & $\mathrm{p} K_{\mathrm{a}}$ & \multicolumn{2}{c}{$k_{\mathrm{N}} / \mathrm{M}^{-1} \mathrm{~s}^{-1}$} \\
\cline { 4 - 5 } & & $\mathbf{1}$ & $\mathbf{2}$ \\
\hline 1. & $4-\mathrm{O}^{-}$ & 11.30 & $822 \pm 7$ & $8720 \pm 390$ \\
2. & $4-\mathrm{NMe}_{2}$ & 9.12 & $43.0 \pm 0.3$ & $2630 \pm 89$ \\
3. & $4-\mathrm{NH}_{2}$ & 8.93 & $32.0 \pm 0.5$ & $2520 \pm 34$ \\
4. & $3,4-\mathrm{Me}_{2}$ & 5.78 & $(7.25 \pm 0.04) \times 10^{-2}$ & $17.4 \pm 0.16$ \\
5. & $4-\mathrm{Me}$ & 5.53 & $(4.69 \pm 0.07) \times 10^{-2}$ & $9.11 \pm 0.14$ \\
6. & $3-\mathrm{Me}$ & 5.09 & $(1.67 \pm 0.02) \times 10^{-2}$ & $3.83 \pm 0.02$ \\
7. & $\mathrm{H}$ & 4.73 & $(8.61 \pm 0.05) \times 10^{-3}$ & $2.07 \pm 0.03$ \\
8. & $3-\mathrm{Cl}$ & 2.14 & - & $(1.40 \pm 0.02) \times 10^{-2}$ \\
\hline
\end{tabular}

${ }^{a}$ The $k_{\mathrm{N}}$ values for the reactions of 1 were taken from ref. $7 \mathrm{a}$.

\section{Results and Discussion}

All reactions in this study obeyed pseudo-first-order kinetics in the presence of a large excess of pyridine. Pseudo-first-order rate constants $\left(k_{\text {obsd }}\right)$ were determined from the equation $\ln \left(A_{\infty}-\right.$ $\left.A_{t}\right)=-k_{\text {obsd }} t+C$. The correlation coefficient for the linear regression was usually higher than 0.9995 . The plots of $k_{\text {obsd }} v s$. pyridine concentration were linear passing through the origin, indicating that the contribution of $\mathrm{H}_{2} \mathrm{O}$ and/or $\mathrm{OH}^{-}$ion from hydrolysis of pyridine to $k_{\text {obsd }}$ is negligible. Thus, the second-order rate constants $\left(k_{\mathrm{N}}\right)$ were determined from the slope of the linear plots of $k_{\text {obsd }} v s$. [pyr] as shown in eq (1), in which [pyr] represents the concentration of pyridine. The uncertainty in the $k_{\mathrm{N}}$ values is estimated to be less than $3 \%$ from replicate runs. The $k_{\mathrm{N}}$ values determined in this study are summarized in Table 1 together with those reported previously for the corresponding reactions of $\mathbf{1}$ for comparison purpose.

$$
k_{\mathrm{obsd}}=k_{\mathrm{N}}[\mathrm{pyr}]
$$

Effect of nonleaving group on reactivity. Table 1 shows that 2 is more reactive than $\mathbf{1}$. It is noted that the reactivity difference becomes larger as the basicity of pyridine decreases, e.g., the reactivity ratio $k_{\mathrm{N}}(2) / k_{\mathrm{N}}(\mathbf{1})$ increases from $c a$. 10 to 80 and 240 as the $\mathrm{p} K_{\mathrm{a}}$ of the conjugate acids of pyridines decreases from 11.30 to 8.93 and 4.73 , in turn.

One can propose three plausible factors (e.g., steric, resonance, and inductive effects) to account for the reactivity difference. It is well known that rates of nucleophilic substitution reactions are strongly influenced by steric effect. The steric constant $\left(\mathrm{E}_{\mathrm{S}}\right)$ of $\mathrm{PhO}$ is not available but is expected to be similar to that of $\mathrm{PhCH}_{2}\left(\mathrm{E}_{\mathrm{S}}=-0.38\right) .{ }^{15 \mathrm{~b}}$ Since the $\mathrm{E}_{\mathrm{S}}$ value of $\mathrm{Ph}$ is $-2.55{ }^{15}$ one can suggest that $\mathrm{PhO}$ is much less bulkier than $\mathrm{Ph}$. Thus, the reduced steric effect might be attributed to the high reactivity of 2. However, 4-nitrophenyl acetate has been reported to be less reactive than 4-nitrophenyl phenyl carbonate toward a series of primary amines, ${ }^{16}$ although $\mathrm{CH}_{3}$ would exert less steric hindrance than $\mathrm{PhO}$. Accordingly, other than steric effect is also responsible for the reactivity difference between $\mathbf{1}$ and $\mathbf{2}$.
In nucleophilic substitution reactions of aryl X-substituted benzoates and related compounds, we found that substrates possessing an EDG in the nonleaving group exhibit lower reactivity than would be expected from the Hammett substituent constant. ${ }^{5,7,12-14}$ Since substrates possessing a $\pi$-electron donating group can be stabilized through resonance interactions as shown in resonance structures I and II, stabilization of the substrate has been concluded to be responsible for the decreased reactivity. $5,7,12-14$

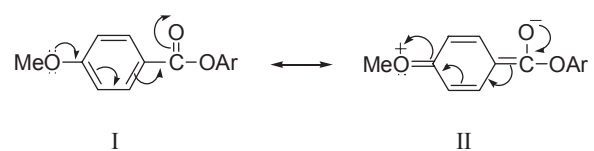

Since similar resonance structures are possible for $\mathbf{2}$ (but absent for 1) as illustrated in resonance structures III and IV, one might expect that $\mathbf{2}$ is less reactive than $\mathbf{1}$. However, the fact that $\mathbf{2}$ is more reactive than $\mathbf{1}$ indicates that the resonance effect cannot be significant in the current reactions. Thus, one can conclude that inductive effect is more significant than resonance effect in the present system (i.e., $\mathrm{PhO}$ behaves as a stronger EWG than $\mathrm{Ph}$ ).

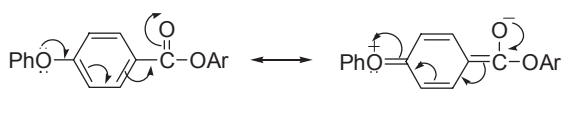

III

IV

Reaction mechanism. To investigate the reaction mechanism, Brønsted-type plot for the reactions of $\mathbf{2}$ has been constructed together with the one for the corresponding reactions of $\mathbf{1}$ for comparison purpose. As shown in Figure 1, the plot for the reactions of $\mathbf{2}$ is nonlinear. Such a nonlinear Brønsted-type plot is typical for reactions reported to proceed through a stepwise mechanism with a change in RDS. ${ }^{1-14}$ In fact, the nonlinear Brønsted-type plot for the reactions of $\mathbf{1}$ has been reported as evidence for a stepwise mechanism with a change in RDS. ${ }^{7 \text { a }}$

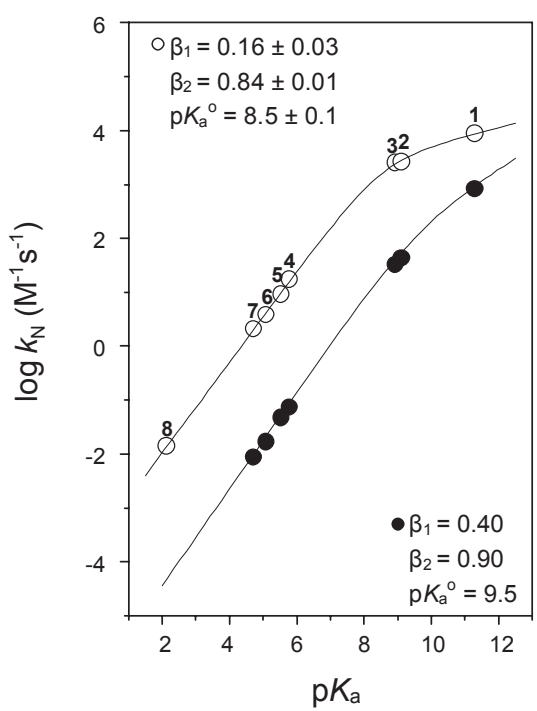

Figure 1. Brønsted plots for reactions of 2,4-dinitrophenyl benzoate 1 $(\bullet)$ and 2,4-dinitrophenyl phenyl carbonate 2 (०) with Z-substituted pyridines in $80 \mathrm{~mol} \% \mathrm{H}_{2} \mathrm{O} / 20 \mathrm{~mol} \% \mathrm{DMSO}$ at $25.0 \pm 0.1{ }^{\circ} \mathrm{C}$. The identity of numbers is given in Table 1. 
Thus, one can suggest that pyridinolysis of $\mathbf{2}$ proceeds also through a stepwise mechanism with a change in RDS upon changing the basicity of pyridines.

Figure 1 illustrates that the reactions of 2 result in a lower $\mathrm{p} K_{\mathrm{a}}^{\mathrm{o}}$ than those of $\mathbf{1}$, although $\mathbf{2}$ is more reactive than $\mathbf{1}$ (i.e., $\mathrm{p} K_{\mathrm{a}}{ }^{\mathrm{o}}=$ 9.5 for 1 and $\mathrm{p} K_{\mathrm{a}}{ }^{\circ}=8.5$ for 2 ). This is in contrast to the report that the substrate possessing an EWG in the nonleaving group is more reactive and results in a higher $\mathrm{p} K_{\mathrm{a}}^{\mathrm{o}}$ than the substrate bearing an EDG. ${ }^{8}$ As illustrated in model V, Jencks et al. have suggested that an EWG in the nonleaving group pulls the nonbonding electrons in the oxygen atom of the leaving aryloxide. Since such pull and push would increase $k_{-1}$ but decrease $k_{2}$, it has been concluded that a decrease in the $k_{2} / k_{-1}$ ratio is responsible for the increased $\mathrm{p} K_{\mathrm{a}}^{\mathrm{o}}$ value observed for the reactions of substrates possessing an EWG in the nonleaving group. ${ }^{8}$
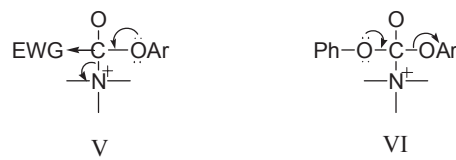

On the other hand, the push by the nonleaving group to accelerate expulsion of the leaving group from $\mathrm{T}^{ \pm}$is also possible as illustrated in model VI. Furthermore, $\mathrm{PhO}$ is a stronger EDG than $\mathrm{Ph}$ on the basis of their $\sigma_{\mathrm{R}}$ values. Thus, one might expect that the reactions of $\mathbf{2}$ would result in a larger $k_{2} / k_{-1}$ ratio than the reactions of $\mathbf{1}$. This appears to be consistent with the fact that the reactions of $\mathbf{2}$ result in a lower $\mathrm{p} K_{\mathrm{a}}{ }^{\mathrm{o}}$ than those of 1 . To examine this idea, the $k_{\mathrm{N}}$ values have been dissected into the microscopic rate constants (e.g., $k_{1}$ and $k_{2} / k_{-1}$ ratios) in the following section.

Dissection of $\boldsymbol{k}_{\mathrm{N}}$ into microscopic rate constants. The nonlinear Brønsted-type plot for the reactions of $\mathbf{2}$ has been analyzed using a semiempirical equation (eq 2) reported by Castro ${ }^{17}$ and Jencks ${ }^{8}$ on the basis of the proposed mechanism shown in Scheme 1. The parameters $\beta_{1}$ and $\beta_{2}$ represent the slope of the curved Brønsted plots in Figure 1 for the reactions with strongly basic and weakly basic pyridines, respectively. Here $k_{\mathrm{N}}{ }^{0}$ refers to the $k_{\mathrm{N}}$ value at $\mathrm{p} K_{\mathrm{a}}^{\mathrm{o}}$ where $k_{2} / k_{-1}=1$. The parameters determined from the fitting of eq (2) to the experimental points are $\beta_{1}=0.16, \beta_{2}=0.84$ and $\mathrm{p} K_{\mathrm{a}}^{\mathrm{o}}=8.5$ for the reactions of 2 , while the parameters reported previously for the corresponding reactions of 1 are $\beta_{1}=0.40, \beta_{2}=0.90$, and $\mathrm{p} K_{\mathrm{a}}^{\mathrm{o}}=9.5$.

$$
\begin{aligned}
& \log \left(k_{\mathrm{N}} / k_{\mathrm{N}}^{\mathrm{o}}\right)=\beta_{2}\left(\mathrm{p} K_{\mathrm{a}}-\mathrm{p} K_{\mathrm{a}}^{\mathrm{o}}\right)-\log (1+\alpha) / 2 \\
& \text { where } \log \alpha=\left(\beta_{2}-\beta_{1}\right)\left(\mathrm{p} K_{\mathrm{a}}-\mathrm{p} K_{\mathrm{a}}^{\mathrm{o}}\right)
\end{aligned}
$$

The apparent second-order rate constant $k_{\mathrm{N}}$ can be expressed as eq (3) by applying the steady-state conditions to the intermediate on the basis of the proposed mechanism. The $k_{2} / k_{-1}$ ratios associated with the reactions of $\mathbf{2}$ have been determined using eqs (4) - (9) and the kinetic data in Table 1. Since eq (3) can be simplified to eq (4) or (5), $\beta_{1}$ and $\beta_{2}$ can be expressed as eqs (6) and (7), respectively.

$$
\begin{aligned}
& k_{\mathrm{N}}=k_{1} k_{2} /\left(k_{-1}+k_{2}\right) \\
& k_{\mathrm{N}}=k_{1} k_{2} / k_{-1}, \text { when } k_{2}<<k_{-1}
\end{aligned}
$$

$$
\begin{aligned}
k_{\mathrm{N}} & =k_{1}, \text { when } k_{2}>>k_{-1} \\
\beta_{1} & =\mathrm{d}\left(\log k_{1}\right) / \mathrm{d}\left(\mathrm{p} K_{\mathrm{a}}\right) \\
\beta_{2} & =\mathrm{d}\left(\log k_{1} k_{2} / k_{-1}\right) / \mathrm{d}\left(\mathrm{p} K_{\mathrm{a}}\right) \\
& =\beta_{1}+\mathrm{d}\left(\log k_{2} / k_{-1}\right) / \mathrm{d}\left(\mathrm{p} K_{\mathrm{a}}\right)
\end{aligned}
$$

Eq (7) can be rearranged as eq (8). Integral of eq (8) from $\mathrm{p} K_{\mathrm{a}}^{\mathrm{o}}$ to $\mathrm{p} K_{\mathrm{a}}$ results in eq (9). Since $k_{2}=k_{-1}$ at $\mathrm{p} K_{\mathrm{a}}^{\mathrm{o}}$, the term $(\log$ $\left.k_{2} / k_{-1}\right)_{\mathrm{pKa}}{ }^{\circ}$ is zero. Therefore, one can calculate the $k_{2} / k_{-1}$ ratios from eq (9) using $\mathrm{p} K_{\mathrm{a}}^{\mathrm{o}}=8.5, \beta_{1}=0.16$, and $\beta_{2}=0.84$ for the reactions of 2.

$$
\begin{aligned}
& \beta_{2}-\beta_{1}=\mathrm{d}\left(\log k_{2} / k_{-1}\right) / \mathrm{d}\left(\mathrm{p} K_{\mathrm{a}}\right) \\
& \left(\log k_{2} / k_{-1}\right)_{\mathrm{p} K \mathrm{a}}=\left(\beta_{2}-\beta_{1}\right)\left(\mathrm{p} K_{\mathrm{a}}-\mathrm{p} K_{\mathrm{a}}^{\mathrm{o}}\right)
\end{aligned}
$$

The $k_{1}$ values have been determined from eq (10) using the $k_{\mathrm{N}}$ values in Table 1 and the $k_{2} / k_{-1}$ ratios calculated above. The $k_{2} / k_{-1}$ ratios and $k_{1}$ values for the reactions of $\mathbf{2}$ are summarized in Table 2. The corresponding values reported previously for the reactions of 1 are also given in Table 2 for comparison purpose.

$$
k_{\mathrm{N}}=k_{1} k_{2} /\left(k_{-1}+k_{2}\right)=k_{1} /\left(k_{-1} / k_{2}+1\right)
$$

As shown in Table 2, 2 exhibits larger $k_{1}$ values than 1 regardless of the pyridine basicity. In contrast, the magnitude of $k_{2} / k_{1}$ ratios is dependent on the basicity of pyridines, i.e., the reaction of $\mathbf{2}$ results in a lager $k_{2} / k_{1}$ ratio than that of 1 when $\mathrm{p} K_{\mathrm{a}} \geq 5.76$ but a smaller one when $\mathrm{p} K_{\mathrm{a}} \leq 5.32$. Thus, one can suggest that the higher reactivity shown by 2 is mainly due to its larger $k_{1}$. Besides, the fact that $\mathbf{2}$ exhibits a larger $k_{1}$ than 1 supports the preceding conclusion that $\mathrm{PhO}$ behaves as a stronger EWG than Ph.

The effect of pyridine basicity on $k_{1}$ is illustrated in Figure 2 . The Brønsted-type plot for the reactions of $\mathbf{2}$ exhibits excellent linear correlation with $\beta_{1}=0.16$. The plot for the corresponding reactions of 1 is also linear with $\beta_{1}=0.40$. It is generally under-

Table 2. Summary of microscopic rate constants $\left(k_{1}\right.$ and $k_{2} / k_{-1}$ ratio $)$ for reactions of 2,4-dinitrophenyl benzoate (1) and 2,4-dinitrophenyl phenyl carbonate (2) with Z-substituted pyridines in $80 \mathrm{~mol} \% \mathrm{H}_{2} \mathrm{O} /$ $20 \mathrm{~mol} \% \mathrm{DMSO}$ at $25.0 \pm 0.1{ }^{\circ} \mathrm{C}^{a}$

\begin{tabular}{lccccccc}
\hline & \multirow{2}{nnnnnyy}{} & $\mathrm{Z}$ & $\mathrm{p} K_{\mathrm{a}}$ & \multicolumn{2}{c}{$k_{\mathrm{N}} / \mathrm{M}^{-1} \mathrm{~s}^{-1}$} & & \multicolumn{2}{c}{$k_{2} / k_{-1}$} \\
\cline { 7 - 8 } \cline { 6 - 7 } & & 1 & 2 & & 1 & 2 \\
\hline 1. & $4-\mathrm{O}^{-}$ & 11.30 & 925 & 8830 & & 7.94 & 80 \\
2. & $4-\mathrm{NMe}_{2}$ & 9.12 & 109 & 3620 & & $6.46 \times 10^{-1}$ & 2.64 \\
3. & $4-\mathrm{NH}_{2}$ & 8.93 & 93.7 & 3810 & & $5.19 \times 10^{-1}$ & 1.96 \\
4. & $3,4-\mathrm{Me}_{2}$ & 5.78 & 5.32 & 1250 & & $1.38 \times 10^{-2}$ & $1.41 \times 10^{-2}$ \\
5. & $4-\mathrm{Me}$ & 5.53 & 4.58 & 962 & & $1.04 \times 10^{-2}$ & $9.60 \times 10^{-3}$ \\
6. & $3-\mathrm{Me}$ & 5.09 & 2.70 & 802 & & $6.24 \times 10^{-3}$ & $4.80 \times 10^{-3}$ \\
7. & $\mathrm{H}$ & 4.73 & 2.10 & 760 & & $4.12 \times 10^{-3}$ & $2.73 \times 10^{-3}$ \\
8. & $3-\mathrm{Cl}$ & 2.14 & - & 306 & & - & $4.73 \times 10^{-5}$ \\
\hline
\end{tabular}

${ }^{a}$ The data for the reactions of 1 were taken from ref. $7 \mathrm{a}$. 


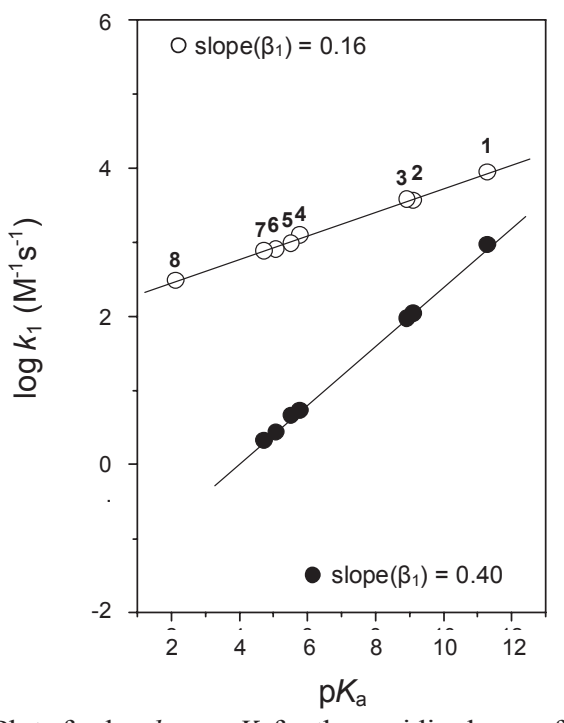

Figure 2. Plots for $\log k_{1} v s$. $\mathrm{p} K_{\mathrm{a}}$ for the pyridinolyses of 2,4-dinitrophenyl benzoate $\mathbf{1}(\bullet)$ and 2,4-dinitrophenyl phenyl carbonate $\mathbf{2}(\mathrm{O})$ in $80 \mathrm{~mol} \% \mathrm{H}_{2} \mathrm{O} / 20 \mathrm{~mol} \% \mathrm{DMSO}$ at $25.0 \pm 0.1{ }^{\circ} \mathrm{C}$. The identity of numbers is given in Table 2 .

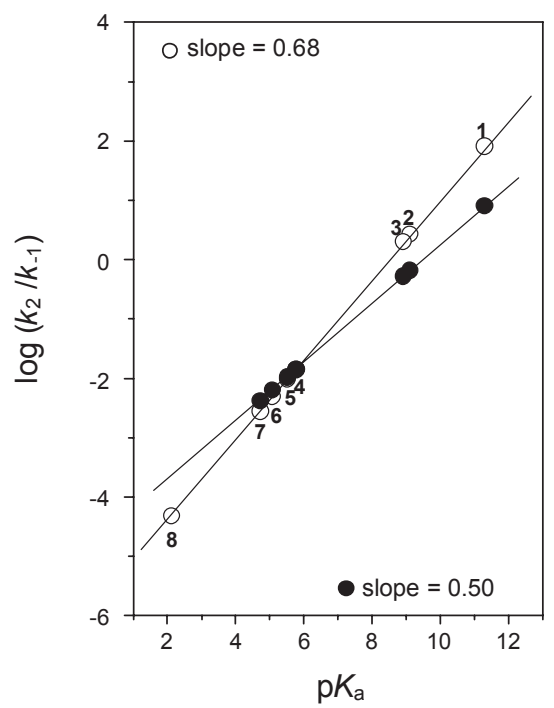

Figure 3. Plots for $\log k_{2} / k_{-1} v s$. $\mathrm{p} K_{\mathrm{a}}$ for the pyridinolyses of 2,4-dinitrophenyl benzoate $\mathbf{1}(\bullet)$ and 2,4-dinitrophenyl phenyl carbonate $\mathbf{2}(\mathrm{O})$ in $80 \mathrm{~mol} \% \mathrm{H}_{2} \mathrm{O} / 20 \mathrm{~mol} \% \mathrm{DMSO}$ at $25.0 \pm 0.1{ }^{\circ} \mathrm{C}$. The identity of numbers is given in Table 2 .

stood that the magnitude of $\beta_{1}$ values represents a relative degree of bond formation between the nucleophile and the electrophile in the transition state. ${ }^{18}$ Thus, one can suggest that bond formation is much less advanced for the reactions of $\mathbf{2}$ than for those of 1.

The effect of pyridine basicity on the $k_{2} / k_{-1}$ ratio is illustrated in Figure 3. One can see that the $k_{2} / k_{-1}$ ratio increases linearly as the pyridine basicity increases for the reactions of $\mathbf{1}$ and $\mathbf{2}$, although the reaction of $\mathbf{2}$ exhibits a slightly larger slope than that of 1 . It is noted that the $k_{2} / k_{-1}$ ratio is larger for the reaction of 2 than that of 1 when $\mathrm{p} K_{\mathrm{a}} \geq 5.78$ but smaller when $\mathrm{p} K_{\mathrm{a}} \leq$ 5.53 . Clearly, the $k_{2} / k_{-1}$ ratio is independent of the nature of $\mathrm{PhO}$ and $\mathrm{Ph}$. This is consistent with our previous proposal that the electronic nature of the substituent in the nonleaving group does not influence the $k_{2} / k_{-1}$ ratio. ${ }^{12-14}$ Furthermore, the reaction of $\mathbf{2}$ results in a lower $\mathrm{p} K_{\mathrm{a}}{ }^{\circ}$ than that of $\mathbf{1}$, although $\mathrm{PhO}$ behaves as a stronger EWG than $\mathrm{Ph}$ in the current study. This is in contrast to the report that an EWG increases $\mathrm{p} K_{\mathrm{a}}{ }^{\circ}$ by decreasing the $k_{2} / k_{-1}$ ratio, ${ }^{8-11}$ but is consistent with our proposal that $\mathrm{p} K_{\mathrm{a}}^{\mathrm{o}}$ is independent of the nature of the substituent in the nonleaving group. ${ }^{12-14}$

\section{Conclusions}

The current study has allowed us to conclude the following: (1) The reactions of $\mathbf{2}$ result in larger $k_{\mathrm{N}}$ and $k_{1}$ values than those of 1. (2) PhO behaves as a stronger EWG than Ph, indicating that inductive effect is more significant than resonance effect for the current reactions. (3) The curved Brønsted-type plot for the reaction of $\mathbf{2}$ suggests that the reaction proceeds through a stepwise mechanism with a change in RDS. (4) The change of $\mathrm{Ph}$ in 1 by $\mathrm{PhO}$ does not affect the mechanism but decreases $\mathrm{p} K_{\mathrm{a}}^{\mathrm{o}}$ from 9.5 to 8.5. (5) The $k_{2} / k_{-1}$ ratio is independent of the electronic nature of the substituent in the nonleaving group.

\section{Experimental}

Materials. 2,4-Dintrophenyl phenyl carbonate (2) was readily prepared from the reaction of phenyl chloroformate with 2,4dinitrophenol in anhydrous ether under presence of triethylamine. Pyridines and other chemicals were of the highest quality available. Doubly glass distilled water was further boiled and cooled under nitrogen just before use. Due to low solubility of 2 in pure water, aqueous DMSO $\left(80 \mathrm{~mol} \% \mathrm{H}_{2} \mathrm{O} / 20 \mathrm{ml} \%\right.$ DMSO $)$ was used as the reaction medium.

Kinetics. The kinetic study was performed using a UV-vis spectrophotometer for slow reactions (e.g., $t_{1 / 2}>10 \mathrm{~s}$ ) or a stopped-flow spectrophotometer for fast reactions (e.g., $t_{1 / 2}<10 \mathrm{~s}$ ) equipped with a constant temperature circulating bath to maintain the reaction mixture at $25.0 \pm 0.1{ }^{\circ} \mathrm{C}$. The reactions were followed by monitoring the appearance of 2,4-dinitrophenoxide. All the reactions were carried out under pseudo-first- order conditions in which pyridine concentrations were at least 20 times greater than the substrate concentration. The pyridine stock solution of $c a$. $0.2 \mathrm{M}$ was prepared by dissolving 2 equiv. of pyridine and 1 equiv. of standardized $\mathrm{HCl}$ solution to make a self-buffered solution in a $25.0 \mathrm{~mL}$ volumetric flask except 3-chloropyridine.

Typically, the reaction was initiated by adding $5 \mu \mathrm{L}$ of a $0.02 \mathrm{M}$ solution of $\mathbf{2}$ in acetonitrile to a 10 -mm quartz UV cell containing $2.50 \mathrm{~mL}$ of the thermostated reaction mixture made up of solvent and aliquot of the pyridine stock solution. All solutions were transferred by gas-tight syringes. Generally, the pyridine concentration was varied over the range $(5-100) \times$ $10^{-3} \mathrm{M}$, while the substrate concentration was $c a .4 \times 10^{-5} \mathrm{M}$. Pseudo-first-order rate constants $\left(k_{\text {obsd }}\right)$ were calculated from the equation, $\ln \left(A_{\infty}-A_{t}\right)=-k_{\text {obsd }} t+C$. The plots of $\ln \left(A_{\infty}-A_{t}\right)$ vs. time were linear over $90 \%$ of the total reaction. Usually, five different pyridine concentrations were employed and replicate values of $k_{\text {obsd }}$ were determined to obtain the second-order rate constants $\left(k_{\mathrm{N}}\right)$ from the slope of linear plots of $k_{\mathrm{obsd}} v s$. pyridine concentrations. 
Products analysis. 2,4-Dinitrophenoxide was liberated quantitatively and identified as one of the products in the reaction of $\mathbf{2}$ by comparison of the UV-vis spectrum after completion of the reaction with that of authentic sample under the same reaction condition.

Acknowledgments. This research was supported by Basic Science Research Program through the National Research Foundation of Korea (NRF) funded by the Ministry of Education, Science and Technology (2009-0075488).

\section{References}

1. (a) Menger, F. M.; Smith, J. H. J. Am. Chem. Soc. 1972, 94, 38243829. (b) Jencks, W. P. Chem. Rev. 1985, 85, 511-527. (c) Castro, E. A. Chem. Rev. 1999, 99, 3505-3524.

2. (a) Page, M. I.; Williams, A. Organic and Bio-organic Mechanisms; Longman: Singapore, 1997; Chapter 7. (b) Maude, A. B.; Williams, A. J. Chem. Soc., Perkin Trans. 1997, 2, 179-183.

3. (a) Castro, E. A. Pure Appl. Chem. 2009, 81, 685-696. (b) Castro, E. A.; Gazitua, M.; Rios, P.; Tobar, P.; Santos, J. G. J. Phys. Org. Chem. 2009, 22, 443-448. (c) Castro, E. A.; Acuna, M.; Soto, C.; Trujillo, C.; Vasquez, B.; Santos, J. G. J. Phys. Org. Chem. 2008, 21, 816-822. (d) Castro, E. A.; Aliaga, M.; Santos, J. G. J. Phys. Org. Chem. 2008, 21, 271-278. (e) Castro, E. A.; Echevarria, G. R.; Opazo, A.; Robert, P.; Santos, J. G. J. Phys. Org. Chem. 2006, 19, 129-135.

4. (a) Sung, D. D.; Jang, H. M.; Jang, D. I.; Lee, I. J. Phys. Org. Chem. 2008, 21, 1014-1019. (b) Oh, H. K.; Lee, J. M.; Lee, H. W.; Lee, I. Int. J. Chem. Kinet. 2004, 36, 434-440. (c) Oh, H. K.; Ku, M. H.; Lee, H. W.; Lee, I. J. Org. Chem. 2002, 67, 8995-8998. (d) Han, J. K.; Han, K. L.; Lee, H. W.; Lee, I. J. Org. Chem. 2000, 65, 47064711.

5. (a) Um, I. H.; Park, Y. M.; Fujio, M.; Mishima, M.; Tsuno, Y. J. Org. Chem. 2007, 72, 4816-4821. (b) Um, I. H.; Kim, E. Y.; Park, H. R. Jeon, S. E. J. Org. Chem. 2006, 71, 2302-2306. (c) Um, I. H.; Lee, J. Y.; Whang Lee, H.; Nagano, Y.; Fujio, M.; Tsuno, Y. J. Org. Chem. 2005, 70, 4980-4987. (d) Um, I. H.; Lee, E. J.; Seok, J. A.; Kim, K. H. J. Org. Chem. 2005, 70, 7530-7536.

6. (a) Um, I. H.; Kim, S. I.; Baek, H. W. Bull. Korean Chem. Soc. 2009, 30, 2909-2912.(b) Um, I. H.; Akhtar, K. Bull. Korean Chem. Soc. 2008, 29, 772-776. (c) Um, I. H.; Min, S. W.; Chun, S. M. Bull.
Korean Chem. Soc. 2008, 29, 1359-1363. (d) Um, I. H.; Seo, J. A.; Lee, H. M. Bull. Korean Chem. Soc. 2008, 29, 1915-1919.

7. (a) Um, I. H.; Baek, M. H.; Bae, S. Y. J. Org. Chem. 2004, 69, 63656370. (b) Um, I. H.; Baek, M. H.; Han, H. J. Bull. Korean Chem. Soc. 2003, 24, 1245-1250.

8. Gresser, M. J.; Jencks, W. P. J. Am. Chem. Soc. 1977, 99, 69706980.

9. (a) Castro, E. A.; Valdivia, J. L. J. Org. Chem. 1986, 51, 16681672. (b) Castro, E. A.; Santander, C. L. J. Org. Chem. 1985, 50, 3595-3600. (c) Castro, E. A.; Steinfort, G. B. J. Chem. Soc., Perkin Trans. 1983, 2, 453-457.

10. (a) Castro, E. A.; Aguayo, R.; Bessolo, J.; Santos, J. G. J. Org. Chem. 2005, 70, 7788-7791. (b) Castro, E. A.; Aguayo, R.; Bessolo, J.; Santos, J. G. J. Org. Chem. 2005, 70, 3530-3536. (c) Castro, E. A.; Vivanco, M.; Aguayo, R.; Santos, J. G. J. Org. Chem. 2004, 69, 5399-5404. (d) Castro, E. A.; Aguayo, R.; Santos, J. G. J. Org. Chem. 2003, 68, 8157-8161.

11. (a) Oh, H. K.; Kim, S. K.; Lee, H. W.; Lee, I. New J. Chem. 2001, 25, 313-317. (b) Oh, H. K.; Kim, S. K.; Cho, I. H.; Lee, H. W.; Lee, I. J. Chem. Soc., Perkin Trans. 2000, 2, 2306-2310. (c) Lim, W. M.; Kim, W. K.; Jung, H. J.; Lee, I. Bull. Korean Chem. Soc. $1995,16,252-256$.

12. (a) Um, I. H.; Hong, J. Y.; Seok, J. A. J. Org. Chem. 2005, 70, 14381444. (b) Um, I. H.; Chun, S. M.; Chae, O. M.; Fujio, M.; Tsuno, Y. J. Org. Chem. 2004, 69, 3166-3172. (c) Um, I. H.; Hong, J. Y.; Kim, J. J.; Chae, O. M.; Bea, S. K. J. Org. Chem. 2003, 68, 51805185.

13. (a) Um, I. H.; Kim, K. H.; Park, H. R.; Fujio, M.; Tsuno, Y. J. Org. Chem. 2004, 69, 3937-3942. (b) Um, I. H.; Min, J. S.; Ahn, J. A.; Hahn, H. J. J. Org. Chem. 2000, 65, 5659-5663.

14. (a) Um, I. H.; Hwang, S. J.; Baek, M. H.; Park, E. J. J. Org. Chem. 2006, 71, 9191-9197. (b) Um, I. H.; Lee, J. Y.; Ko, S. H.; Bea, S. K. J. Org. Chem. 2006, 71, 5800-5803.

15. (a) Isaacs, N. S. Physical Organic Chemistry; Longman: England, 1995; p 153. (b) Lowry, T. H; Richardson, K. S. Mechanism and Theory in Organic Chemistry; Harper Collins: New York, 1987; $\mathrm{p} 153$.

16. Um, I. H.; Park, H. R.; Kim, E. Y. Bull. Korean Chem. Soc. 2003, 24, 1251-1255.

17. Castro, E.; Moodie, R. B. I. Chem. Soc., Chem. Commun. 1973, 828-829.

18. (a) Carroll, F. A. Perspectives on Structure and Mechanism in Organic Chemistry; Brooks/Cole: New York, 1998. (b) Jencks, W. P. Catalysis in Chemistry and Enzymology; McGraw-Hill: New York, 1969. 